\title{
A ABORDAGEM PIKLER E A ORGANIZAÇÃO DO ESPAÇO PARA BEBÊS NA EDUCAÇÃO INFANTIL
}

\author{
Renata Pavesi Cocito
}

Universidade Estadual Paulista - UNESP, campus de Presidente Prudente, SP. E-mail: renatapavesi@hotmail.com

\section{RESUMO}

O artigo é proveniente dos estudos realizados sobre a abordagem Pikler para promover a formação de professores e aprimoramento do trabalho desenvolvido em uma creche universitária, tendo como enfoque a organização dos espaços para bebês. $O$ objetivo é apresentar contribuições piklerianas para a organização do espaço institucional para bebês (crianças com até 1 ano e 6 meses de idade). Como metodologia adotamos a pesquisa bibliográfica. A abordagem Pikler tem origem em Budapeste com a médica húngara Emmi Pikler que conduziu os trabalhos de educação e cuidados de crianças órfãs a partir de 1946. Ao estudar a abordagem Pikler entendemos o espaço como suporte para apoiar os bebês em suas aquisições motoras e na sua inserção no mundo. $O$ espaço amplo, com pouco, mas adequado mobiliário e com materiais pensados e selecionados para as especificidades da faixa etária, possibilita que o bebê vivencie o espaço com o seu corpo e, desta maneira, consiga gradualmente perceber e se inserir no mundo que o rodeia. As ações de organização do espaço, à luz da abordagem Pikler, coloca o bebê no centro do processo pedagógico e suprimi a evidência e protagonismo do adulto, ainda tão presente nesta etapa da Educação Básica. O bebê, potente, capaz e atuante, precisa de um contexto que o apóie e o permita vivenciar a sua infância com liberdade e cuidados.

Palavras Chave: Educação Infantil - abordagem Pikler - bebês - espaço - organização espacial

\section{THE PIKLER APPROACH AND THE ORGANIZATION OF BABY SPACE IN CHILD EDUCATION}

\begin{abstract}
The article comes from the studies carried out on the Pikler approach to promote teacher training and improvement of the work developed in a university day care center, focusing on the organization of spaces for babies. The objective is to present piklerian contributions for the organization of the institutional space for infants (children up to 1 year and 6 months of age). As methodology, we adopted bibliographic research. The Pikler approach originated in Budapest with the Hungarian physician Emmi Pikler who conducted the education and care of orphaned children from 1946. In studying the Pikler approach we understand space as a support to support babies in their motor acquisitions and their insertion in the world. The ample space, with little but adequate furniture and materials thought and selected for the specifics of the age range, allows the baby to experience the space with his body and, in this way, can gradually perceive and insert himself in the world that surrounds him. The actions of space organization, in the light of the Pikler approach, place the baby at the center of the pedagogical process and suppress the evidence and protagonism of the adult, still so present in this stage of Basic Education. The baby, powerful, capable and active, needs a context that supports him and allows him to experience his childhood with freedom and care.
\end{abstract}

Keywords: Child education - approach Pikler - babies - space - space organization 


\section{INTRODUÇÃO}

O artigo é proveniente dos estudos realizados sobre a abordagem Pikler para promover a formação de professores e aprimoramento do trabalho desenvolvido em uma creche universitária, tendo como enfoque a organização dos espaços para bebês.

A abordagem Pikler foi escolhida para subsidiar o trabalho na instituição por oferecer elementos teóricos e práticos acerca da educação e cuidados dos bebês, com ênfase no desenvolvimento motor autônomo, possibilitando que a ação docente, no que tange a organização do espaço, possa ser estruturada respeitando as características de crianças de até 18 meses de idade.

Esta abordagem tem origem em Budapeste com a médica húngara Emmi Pikler que conduziu os trabalhos de educação e cuidados de crianças órfãs a partir de 1946 (FALK, 2010), no Instituto Lóczy, hoje chamado Instituto Emmi Pikler.

Acreditamos que as práticas relacionadas à Educação Infantil no Brasil, mesmo tendo leis que amparam, ainda se edificam em ações e práticas de senso comum. Evidenciamos também que os espaços institucionais muitas vezes são adaptados e/ou não são adequados para o uso dos bebês. Considerando ainda que muitas crianças ficam até 10 horas por dia nas instituições, o espaço que ocupam se torna algo que precisa ser pensado criticamente, com cuidado e atenção aos detalhes. Nesta perspectiva consideramos que pesquisas voltadas para o trabalho institucional com bebês são necessárias e a estruturação do trabalho pedagógico com fundamentação científica é essencial na Educação Infantil.

Este trabalho tem como objetivo apresentar contribuições piklerianas para a organização do espaço institucional para bebês (crianças com até 1 ano e 6 meses de idade).

\section{METODOLOGIA}

A pesquisa caracteriza-se como qualitativa do tipo bibliográfica. Buscamos contribuições para compreendermos a abordagem Pikler e nos fundamentamos em: Kálló e Balog (2017), Soares (2017), Falk (2016), Fochi (2015), Gonzalez-Mena (2015), Gonzalez-Mena e Eyer (2014), Falk (2011). E para os estudos sobre organização do espaço nos embasamos em: Cocito (2017), Ceppi e Zini (2013), Tuan (2013), Barbieri (2012), Carvalho e Rubiano (2008), Horn (2004) e Forneiro (1998).

\section{RESULTADOS}

Na década de 30 a Drâ. Emmi Pikler dedicou-se a estudar o desenvolvimento de bebês e crianças pequenas: "formada em medicina e licenciada em pediatria, em Viena, na década de 20, Pikler postulou conceitos importantes sobre o desenvolvimento motor de bebês, associando-se a aspectos sociais, afetivos e cognitivos [...]" (FOCHI, 2015, p.51). Observando atentamente o desenvolvimento de bebês e crianças pequenas Emmi Pikler, "não acreditava que o ser passivo se tornasse uma pessoa ativa pelo impulso do adulto [...]" (FALK, 2011, p. 19), considerava qualquer tipo de intervenção e instrução do adulto desnecessária.

Com base em suas conviç̧ões, ao nascer seu primeiro filho, Emmi Pikler e seu marido decidem adotar alguns princípios: não acelerar etapas do desenvolvimento, respeito ao ritmo da criança, incentivo a autonomia, movimento e brincar livre. Sobre a educação e cuidados do bebê de Emmi Pikler, a primogênita Anna Tardos, Falk (2011, p.19) evidencia que:

Os pais nunca colocavam o filho numa posição que ele não pudesse adotar e abandonar sozinho; nunca the propunham nem impunham diferentes classes de movimentos e se abstinham de exercer uma influência direta sobre o seu desenvolvimento motor. Em troca, criavam condições para que o filho pudesse passar dias com tranqüilidade e equilíbrio, que tivesse sempre possibilidade de espaços e lugares necessários para a liberdade de 
movimentos - inclusive mais possibilidades do que aquelas que a criança pudesse aproveitar naquele momento.

Emmi Pikler passou a trabalhar com pediatria familiar e desenvolveu este trabalho, orientando famílias por mais de 10 anos. Em 1940 ela publica seu primeiro livro: O que sabe fazer o seu recémnascido? E logo após o fim da 2a Guerra Mundial (1945), Emmi Pikler passa a coordenar um orfanato, localizado na Rua Lóczy em Budapeste na Hungria. É neste local que todos os ideais da Drá. Emmi Pikler se consolidam, se tornando uma referência para a educação e cuidados de crianças em diversas partes do Mundo (FALK, 2011).

Suas pesquisas permitiram que o desenvolvimento motor autônomo da criança, um dos eixos estruturantes de sua abordagem, fosse descrito de maneira minuciosa através de 10 fases: partindo do decúbito dorsal (fase 1) e chegando ao caminhar (fase 10): a criança passa da postura dorsal para a elaboração do rolar a partir de movimentos laterais repetitivos até atingir a postura ventral (de bruços), posteriormente desloca-se arrastando, engatinhando e exercita a escalada, concomitantemente permite-se ficar na postura de lado acotovelada, semisentada com apoio da mão, e com as pernas flexionadas para trás e pernas flexionadas (a base de apoio vai diminuindo a medida que ganha equilíbrio e segurança). A partir da conquista desses movimentos posturais e, consegue manter-se de quatro apoios, de joelho e gradativamente em pé com apoio e, por fim, ergue-se sem apoio e consegue consolidar a marcha.

A conquista postural e motriz, que passa da horizontalidade/deitada para a verticalidade/caminhar, é desenvolvida numa suceção de movimentos entrelaçados, onde um depende do outro para se consolidar. Soares (2017, p. 51) destaca que:

Emmi Pikler observou, em suas pesquisas, que as crianças que se movem em liberdade seguem a mesma seqüência de posições baseadas na maturidade biológica e raramente pulam etapas, embora existam diferenças individuais importantes no ritmo desse desenvolvimento.

Por isso, Pikler evidenciava que não há necessidade de estímulos e intervenção do adulto, pois o bebê é capaz de assumir posturas corporais de forma autônoma, condizente com o seu ritmo e desenvolvimento físico e cognitivo. Colocar o bebê em uma superfície firme e na posição deitada, com as costas sobre o chão, é a postura ideal para o bebê. Desta forma ele se movimentará de acordo com as suas possibilidades. A abordagem Pikler evidencia que nenhum bebê deve ser colocado em uma posição corporal que ainda não tenha a capacidade de assumir sozinho, ou seja, se a criança ainda não consegue assumir a posição sentado se movimentando sozinha elas não deve ser colocada sentada, se ela não se apóia e fica em pé sozinha, não devemos segurá-la pelas mãos e forçá-la a caminhar (Gonzalez-Mena e Eyer, 2014). As posturas corporais são conquistas de cada criança. A modificação da maneira da criança posicionar-se no espaço, permite que ela amplie o seu campo de visão e a sua capacidade de atuação no entorno.

A criança "aprende" o mundo pelo movimento, o seu corpo é a porta de entrada para o mundo que ela encontra "pronto" ao nascer. As oportunidades, oferecidas pelo adulto, é que farão a diferença na sua relação com o mundo e no seu desenvolvimento. Nesta perspectiva, quando estudamos a abordagem Pikler entendemos o espaço como suporte para apoiar os bebês em suas aquisições motoras e na sua inserção no mundo.

\section{DISCUSSÃO}

Quando falamos de organização de espaço estamos nos referindo ao posicionamento, disponibilidade e acessibilidade do mobiliário, materiais e ambientação que compõe determinado local. Esses elementos devem estar relacionados às necessidades dos bebês de maneira que o espaço 
físico possa ser base para um ambiente aconchegante e acolhedor e, assim, ter potencial para ser apropriado e interiorizado, adquirindo o "status" de lugar (lugar = laço afetivo do sujeito com o espaço/ambiente) (TUAN, 2013). Baseada na abordagem Pikler, Gonzalez-Mena (2015, p.185) ressalta que "[...] o ambiente é um professor, indicando que não basta simplesmente ter um espaço amplo para as crianças brincarem e jogas brinquedos de plástico no meio".

Considerando os apontamentos acerca do espaço/ambiente e a necessidade da criança de se movimentar, a primeira inferência que fazemos é que o espaço, necessariamente, precisa permitir a movimentação ampla e a exploração do espaço e dos materiais pelos bebês. Precisamos organizar um espaço de oportunidades de experiências para o bebê.

O espaço amplo, com pouco mobiliário e com materiais pensados e selecionados para as especificidades da faixa etária, possibilita que o bebê vivencie o espaço com o seu corpo e, desta maneira, consiga gradualmente perceber e se inserir no mundo que o rodeia.

Nesta configuração de espaço físico para bebês o chão emerge como um protagonista na organização espacial, um material essencial que merece acuidade pedagógic. Cocito (2017, p.125) evidencia que "quando o espaço for utilizado por bebês, o tipo do piso necessita de mais atenção ainda, haja vista que os pequenos utilizam o chão como um espaço de apoio e exploração para suas vivências na instituição". Kálló e Balog (2017, p.37) evidenciam que "a resistência de um chão duro impulsiona a verticalidade, apoia seus esforços repetidos para manter-se na posição correta e a tonicidade necessária. Do nosso ponto de vista, um chão de espuma é inadequado [...]". Por sua vez, Ceppi e Zini (2013, p.140) consideram o chão "[...] como um dos elementos mais flexíveis e transformáveis para todas as crianças de todas as idades. Essa ampla área de superfície oferece possibilidades intermináveis".

Com relação ao tipo de brinquedos que podemos disponibilizar para os bebês, consideramos pertinente, primeiramente, nos apoiar nas palavras Sommerhalder e Alves (2011, p.15): “o corpo é o nosso primeiro e mais versátil brinquedo". Partindo desta premissa consideramos que os materiais a serem disponibilizados precisam "conversar com o corpo do bebê", portanto para cada faixa etária um tipo de brinquedo ou objeto de brincar (material não estruturado) deve ser oferecido, alinhado as possibilidades e necessidade do bebê. Gonzalez-Mena evidencia que "os brinquedos no Instituto Pikler são simples - criados para explorar e aprender, em vez de simplesmente entreter" (p.185, 2015).

Soares (2017, p.36-38) evidencia que dos 3 a 6 meses o primeiro brinquedo para o bebê é um tecido de $35 \times 35 \mathrm{~cm}$ de cor intensa e estampa clara (preferencialmente bolinha brancas), pois permite que o bebê agarre e explore com autonomia o objeto de brincar; além disso a autora indica objetos leves e fácies de pegar e que permitam a exploração dos sentidos (variando formas, texturas, temperaturas, cores, por exemplo). A partir dos 6 meses materiais mais pesados podem ser oferecidos e as bolas são oferecidas quando já conseguem se deslocar e se direcionar ao objeto desejado. A partir de 1 ano brinquedos e objetos que contribuam com as aquisições motoras de subir, descer e andar são os mais indicados. Esta indicação tem como base o crescimento cefalocaudal e proximodistal:

O desenvolvimento dos bebês se dá da cabeça aos pés e é chamado de desenvolvimento cefalocaudal; isso significa que os bebês começam a controlar primeiro os músculos localizados ao redor da cabeça e, depois, dos músculos localizados mais abaixo. O desenvolvimento também é proximodistal, o que significa do meio às extremidades. Você pode observar essas duas progressões facilmente: os bebês levantam a cabeça antes do peito, controlam os braços antes das mãos, e as mãos antes dos pés. No início seus movimentos são reflexivos: os braços balançam e as mãos seguram sem intenção consciente (Gonzalez-Mena, p.266, 2015). 
Outra proposta que pode ser inserida ao organizarmos um espaço para bebês é o "Cesto dos tesouros". Originalmente criado por Elinor Goldshimied (Goldshimied e Jackson, 2006), esta proposta consiste em fazer uma seleção de objetos de uso cotidiano (exceto os feitos de plástico) e os reunir em um cesto de aproximadamente $35 \mathrm{~cm}$ de diâmetro feito, preferencialmente de material natural. Esses materiais não estruturados tem como finalidade ser uma fonte de aprendizagem e de exploração para o bebê, onde ele possa criar e descobrir diferentes possibilidades e propriedades a partir da manipulação. A utilização do "Cesto dos Tesouros" em um espaço para bebês exige certos critérios e cuidados, um deles diz respeito a observação atenta do professor e ao brincar livre da criança, ou seja, com a supervisão do adulto mas sem a intervenção excessiva.

O mobiliário para o espaço de uso dos bebês pode assumir dupla função: acomodar objetos e ser suporte/apoio seguro para os bebês. Como explicitado anteriormente, o mobiliário pode servir de apoio para o bebê se posicionar verticalmente. Os bebês vão testar as propriedades e possibilidades também da mobília - vão tocar, tentar puxar, empurrar, escalar e se apoiar na mobília, por exemplo por toda estas possibilidades de envolvimento do bebê precisamos de critérios ao dispor o mobiliário, pensar em sua funcionalidade e utilidade para o espaço com bebês. Consideramos que estantes baixas e/ou com base larga (para evitar tombamento) é um mobiliário básico para o espaço de uso dos bebês, se tiver rodízios que os mesmos possam ser travados, que não tenham arestas pontiagudas e/ou farpas.

A exploração da posição vertical pode ser favorecida pelo espaço, Gonzalez-Mena (p.269, 2015) sugere que o ambiente seja planejado “[...] de modo a incluir corrimãos, sofás e mesas baixas o que proporcionar um apoio seguro para as crianças que estiverem ansiosas por ficar em pé mas ainda não conseguem por conta própria".

Destacamos que a abordagem Pikler possui uma série de equipamentos em madeira que podem compor o espaço para bebês, são túneis/labirintos, módulos e rampas em diferentes tamanhos e altura, propícios para o desenvolvimento motor autônomo. Constituem-se em um mobiliário específico que possibilitam a exploração de diferentes capacidades motoras como subir, descer, engatinhar, arrastar-se e ainda permite a construção de alguns conceitos como alto/baixo, dentro/fora, subir/descer. Soares (2017, p. 51) aponta que estes implementos em madeira tem "[...] a finalidade de estimular indiretamente a criança".

No âmbito institucional, a organização do espaço passa pela percepção e ação do professor que precisa edificar um espaço/ambiente “[...] calmo e luminoso que a criança possa explorá-lo livremente, respondendo a suas necessidades de desenvolvimento, afirmação, de confiança em si mesma e de autonomia" (SOARES, 2017, p.31).

O espaço precisa ser seguro o suficiente para que o bebê possa brincar e explorar o entorno, sem a necessidade de ter intervenção constante do professor. O espaço/ambiente edificado pela ação do adulto e pela relação criança-crinça/criança-adulto é uma das condições necessárias para que a criança se desenvolva de maneira equilibrada nos aspectos emocional, afetivo, psicomotor e cognitivo (FALK, 2010).

\section{CONCLUSÕES}

Com base nas aproximações com a abordagem Pikler e na experiência formativa junto com a equipe de trabalho da creche universitária, ficou evidente que os ideais piklerianos contribuem para que a organização do espaço esteja alinhada com o que de fato os bebês precisam. A organização espacial tendo como plano de fundo a abordagem Pikler possibilita um direcionamento assertivo com relação a organização dos espaços para bebês, pois esta fundamentada e alinhada ao seu desenvolvimento integral da criança. A abordagem Pikler nos apresenta possibilidades e caminhos 
possíveis de serem trilhados nas instituições de Educação Infantil que buscam a qualificação de seus espaços e de sua ação docente.

As ações de organização do espaço, à luz da abordagem Pikler, coloca o bebê no centro do processo pedagógico e suprimi a evidência e protagonismo do adulto, ainda tão presente nesta etapa da Educação Básica.

Ressaltamos que um trabalho institucional inspirado na experiência da Dra. Emmi Pikler precisa estar associado e "ancorado" na formação e orientação pedagógica, visto que, interpretações de cunho espontaneísta podem ser tecidas neste contexto, decorrentes do olhar simplista (pouco aprofundado teoricamente). Nesta perspectiva, considerando o âmbito da Educação Infantil, observamos que a prática do professor e sua atenção ao desenvolvimento do bebê é primordial, pois mesmo a criança desenvolvendo os movimentos por iniciativa própria o professor precisa edificar um espaço/ambiente afetivamente favorável para a construção de vínculos afetivos e onde a liberdade seja uma constante.

Neste artigo evidenciamos a organização do espaço físico, no entanto cabe ressaltar que a formação continuada dos profissionais precisa ir além e englobar o modo de acolher o bebê no espaço da instituição, como o adulto deve se posicionar com relação a movimentação do bebê, o quanto deve interferir e o quanto deve "se recolher", enfim, é preciso que o olhar do professor seja humanizado e sensível.

A análise feita por Emmi Pikler acerca do desenvolvimento motor da criança, de sua autonomia postural e motriz comprovam que temos muito para aprender com as crianças e que precisamos confiar na capacidade delas. O bebê, potente, capaz e atuante, precisa de um contexto que o apóie e o permita vivenciar a sua infância com liberdade e cuidados.

\section{REFERÊNCIAS}

CEPPI, G.; ZINI M. (Org.). Crianças, espaços e relações: como projetar ambientes para a Educação Infantil. Porto alegre: Penso, 2013.

COCITO, R.P. Do espaço ao lugar: contribuições para a organização dos espaços para bebês e crianças pequenas. 2017. 185f. Dissertação (Mestrado em Educação) - Faculdade de Ciências e Tecnologia, Universidade Estadual Paulista, Presidente Prudente. Disponível em: https://repositorio.unesp.br/handle/11449/151013 Acesso em: 17/01/2018

FALK, J. (org.) Educar os três primeiros anos: a experiência de Loczy. Ed: Junqueira e Marin. 2011.

FALK, J. (org.). A abordagem Pikler: educação infantil. Coleção 1ạ Infância: educar de 0 a 6. Ed: Omnisciência. 1a Edição, 2016.

FOCHI, P. Afinal, o que os bebês fazem no berçário?: comunicação, autonomia e saber-fazer de bebês em um contexto de vida coletiva. Porto Alegre: Penso, 2015.

FORNEIRO, L.I. A organização dos espaços na educação infantil. In: ZABALZA, M. A. Qualidade em Educação Infantil/ tradução Beatriz Affonso Neves. Porto Alegre: Artmed, 1998.

FRAGO, A.V.; ESCOLANO, A. Currículo, espaço e subjetividade: a arquitetura como programa. Rio de Janeiro: DP\&A, 1998. 
GOLDSCHMIED, E.; JACKSON, S. Educação de 0 a 3 anos. O atendimento em creche. 2. ed. Porto Alegre: Artmed, 2006.

GONZALEZ-MENA; J. Fundamentos da educação Infantil: ensinando crianças em uma sociedade diversificada. 6a Ed. Porto Alegre: Penso, 2015.

GONZALEZ-MENA; J.;EYER, D.W. O cuidado com bebês e crianças pequenas na creche: currículo de educação e cuidados baseado em relações qualificadas. 9ạ Ed. Porto Alegre: Penso, 2014.

KÁLLÓ, E. K.;BALOG, G. As origens do brincar livre. Coleção 1ạ Infância: educar de 0 a 6 . Ed: Omnisciência. 1a Edição, 2017.

HORN, M. da G. de S. Sabores, cores, sons, aromas. A organização dos espaços na educação infantil. Porto Alegre: Artmed, 2004.

SALLES, F.; FARIA, V. Currículo na Educação Infantil: diálogo com os demais elementos da proposta pedagógica. 2.ed. São Paulo: Ática, 2012.

SOARES, S. Vínculo, movimento e autonomia. Coleção 1ạ Infância: educar de 0 a 6. Ed: Omnisciência. 1a Edição, 2017.

SOMMERHALDER, A. ; ALVES, F. D. Jogo e a educação da infância: muito prazer em aprender. Curitiba: CRV, 2011. https://doi.org/10.24824/978858042118.7

TUAN, Y.Espaço e Lugar: a perspectiva da experiência. Tradução: Lívia de Oliveira. Londrina: EDUEL, 2013. 